\title{
Effect of nickel alloying on corrosion and wear resistance of the strain-induced martensitic transformable wear resistant $\mathrm{Fe}-2 \mathrm{Cr}$ - 1.7C-1Si alloy
}

\author{
Ji Hui Kim, Myung Chul Park, Jae Hwan Cho and Seon Jin Kim ${ }^{\text {a }}$ \\ Division of materials science and engineering, Hanyang university, Seoul, 133-791, Korea
}

\begin{abstract}
The strain-induced martensitic transformable wear resistant $\mathrm{Fe}-20 \mathrm{Cr}-1.7 \mathrm{C}-1 \mathrm{Si}$ alloy was investigated with regard to its corrosion and wear behavior with variations in nickel content. Although an amount of 10 wt.\% nickel was not enough to form the passive layers on the surface of the alloys, it was clearly explained that the presence of nickel in the alloy is beneficial to corrosion resistance in the saline medium. Meanwhile, 3 and 5 wt.\% nickelcontaining alloys were almost retained the excellent wear resistance of the nickel-free alloy during the wear test up to 2000 cycles. However, that of 7 and $10 \mathrm{wt} . \%$ nickel-containing alloys were abruptly deteriorated due to lowering the hardness of matrix and being insignificant the role of strain-induced martensitic transformation. Results of the study suggest that the nickel addition was apparently attributable to be beneficial effect on the corrosion resistance of the alloy. However, it was shown that the wear resistance of the alloy contained above $5 \mathrm{wt} . \%$ nickel was remarkably deleterious. Thus, it was demonstrated that $5 \mathrm{wt} . \%$ nickel was the proper quantity which is able to improve corrosion resistance without the loss of wear resistance for the Fe-20Cr-1.7C-1Si alloy at room temperature in air.
\end{abstract}

\section{Introduction}

Various industrial machine elements or tools such as the mining equipment of a mineral deposit, the parts of stone clusters, extruder screws, pump and fan impellers, and machine components are always able to expose a severe damage by abrasive wear, adhesive wear and corrosion. For saving production costs and enabling a longer service life, damaged parts due to these wear and corrosion phenomena may result in enormously consuming money and time for maintenance and reparation. So, the developments of new processes and thermal treatments for alloys have been allowed to solve these problems [1, 2]. However, it may become more essential and preferential that the alloy itself develops and improves in order to incorporate the excellent wear and corrosion properties when operating in aggressive industry environment.

Recently, the wear resistant $\mathrm{Fe}-20 \mathrm{Cr}-1.7 \mathrm{C}-1 \mathrm{Si}$ alloy using strain-induced phase transformation in order to reach the utmost wear resistance has been newly developed. And it has been reported that the alloy has more excellent wear and cavitation erosion resistance than representative commercial Stellite alloys [3, 4]. In the present study, the effects of nickel alloying on the corrosion and wear behavior of Fe-20Cr-1.7C-1Si alloy were investigated in a saline medium and under a high contact stress, respectively. An attempt may suggest a criterion for the effects of alloying elements based on the concept of a wear and corrosion performance.

\section{Experimental procedure}

Fe-20Cr-1.7C-1Si-xNi alloys with x varying from 0.0 to $10.0 \mathrm{wt}$. \% were prepared by vacuum induction melting. The self-mated sliding wear tests were performed under a contact stress of $103 \mathrm{MPa}$ in air at room temperature. The sliding speed of the wear test was $3 \mathrm{~mm} / \mathrm{s}$ and the stroke was $9 \mathrm{~mm}$. The total weight losses of the moving pin and the static plate were measured after 500, 1000 and 2000 cycles, respectively. The friction coefficients during 500 cycles were measured to evaluate the frictional characteristics for the alloys. The worn surfaces of moving specimens after 2000 cycles of sliding were examined by X-ray diffractometer (XRD) in order to investigate the strain-induced martensite formed during wear. In order to evaluate the effect of work hardening by the strain-induced martensitic transformation, the micro-hardness variation beneath the worn surfaces of the alloys were measured after 2000 cycles tested at room temperature in air.

a e-mail: alloylab@hanyang.ac.kr

This is an Open Access article distributed under the terms of the Creative Commons Attribution-Noncommercial License (http://creativecommons.org/licenses/by-nc/3.0/), which permits unrestricted use, distribution, and reproduction in any noncommercial medium, provided the original work is properly cited. 
In order to examine the corrosion resistance, coupons $11 \mathrm{~mm} \times 22 \mathrm{~mm} \times 1.1 \mathrm{~mm}$ in size was prepared for the immersion test in the saline medium. The corrosion resistance is evaluated by measuring its weight loss per unit area. The immersion test was conducted at room temperature for $100 \mathrm{~h}$.

\section{Results and discussion}

In Fig. 1, the sliding wear behaviors of Fe-20Cr-1.7C-1Si-xNi ( $\mathrm{x}=0-10 \mathrm{wt} . \%)$ alloys as a function of sliding cycles are represented. As shown in Fig. 2, in the Ni concentration range below 5 wt. \%, wear loss increased linearly with increasing sliding cycles up to 2000 cycles and no difference in the wear rate was found regardless of Ni concentration. The wear loss was approximately $6.2 \mathrm{mg}$ at 2000 cycles for each alloy. The wear loss of the alloy containing $7 \mathrm{wt}$ \% Ni also increased linearly, however, the wear rate increased about twice in comparison with those in the range below $5 \mathrm{wt}$ \%. In the meanwhile, the wear loss of the alloy containing $10 \mathrm{wt} \% \mathrm{Ni}$ increased abnormally and the wear behavior deviated from the linearity. Namely, the Ni addition in the concentration range below $5 \mathrm{wt}$ \% did not affect the wear resistance of the alloy. However, the Ni addition above the range decreased the wear resistance.

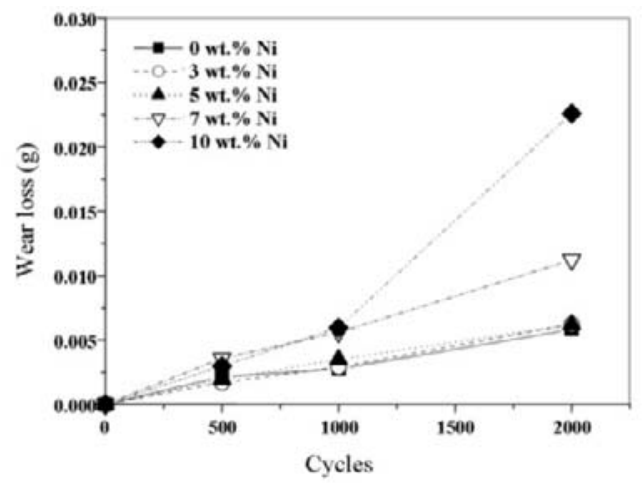

Fig. 1 Wear loss of the alloys after the wear test under a contact stress of $103 \mathrm{MPa}$

Hardness of the alloy decreased from HRc 45 to 30 with increasing the Ni concentration up to 10 wt. \%. Even though the hardness is not a valid criterion for tribological characteristics, most of the researchers claim that wear and friction properties are deteriorated as hardness decreased. So, it was expected that the Ni addition may decrease the wear resistance of the alloy. As can be seen in Fig. 2, the large portion of worn surfaces for the alloys containing 0 and $5 \mathrm{wt} \% \mathrm{Ni}$ was found to retain the smooth surfaces with little plowing in spite of increasing the sliding cycles, and severe plastic deformation was not observed. However, worn surfaces in the alloy containing $10 \mathrm{wt}$. \% Ni were roughened and adhesive junctions enlarged in size. Consequently, when $\mathrm{Ni}$ added above 5 wt. $\%$, the adhesion tendency increased.

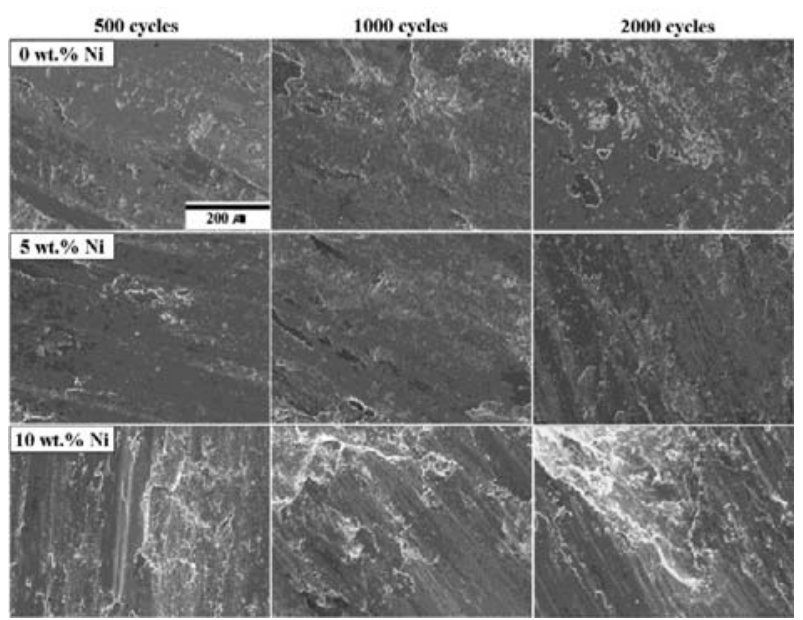

Fig. 2 SEM micrographs of the worn surfaces for Fe-20Cr-1.7C-1Si-xNi alloy (x=0, 5 and 10 wt. \%) 
The change of corrosion resistance for Fe-20Cr-1.7C-1Si alloy with increasing Ni concentration in the saline medium was shown in Fig. 3. Compared with the corrosion rate and the final weight loss for each alloy after the immersion test for 100 hour, they decreased with increasing Ni concentration. The corrosion rate and the weight loss of the alloy containing $10 \mathrm{wt}$. \% Ni decreased significantly below a sixth and a half of those of the Ni-free alloy, respectively. It is clearly demonstrated that the corrosion resistance of $\mathrm{Fe}-20 \mathrm{Cr}-1.7 \mathrm{C}-1 \mathrm{Si}$ alloy was improved with increasing the $\mathrm{Ni}$ concentration in the saline medium. As illustrated in Fig. 4, the Ni addition improved the polarization behavior of $\mathrm{Fe}-20 \mathrm{Cr}-1.7 \mathrm{C}-1 \mathrm{Si}$ alloy in the saline medium. Although both $\mathrm{Ni}$-free and $\mathrm{Ni}$-added alloys exhibited poor polarization behavior and were even anodically active, the Ni addition positively affected the corrosion current density and potential. With increasing Ni concentration, the corrosion current density decreased and the corrosion potential moved toward the noble direction. These electrochemical test results corresponded to the immersion test result. It was considered that the composition of austenite phase became chemically noble, since $\mathrm{Ni}$ was more remained in the austenite phase with increasing $\mathrm{Ni}$ concentration during the solidification. Consequently, a substantial effect on improving inherent corrosion potential and reducing the dissolution rate was accomplished by the Ni addition.

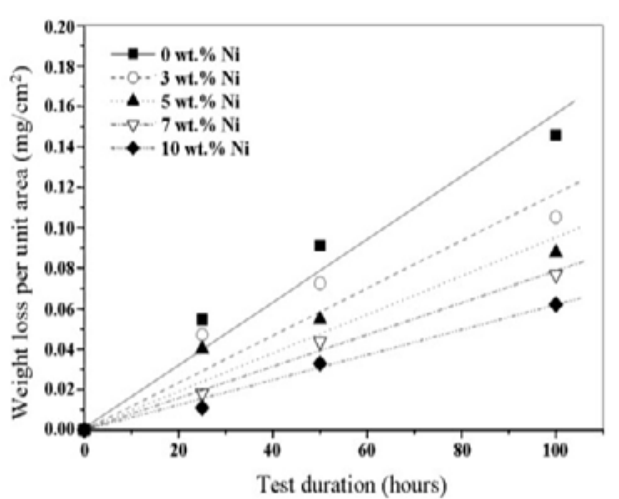

Fig. 3 Results of the immersion test in the saline medium

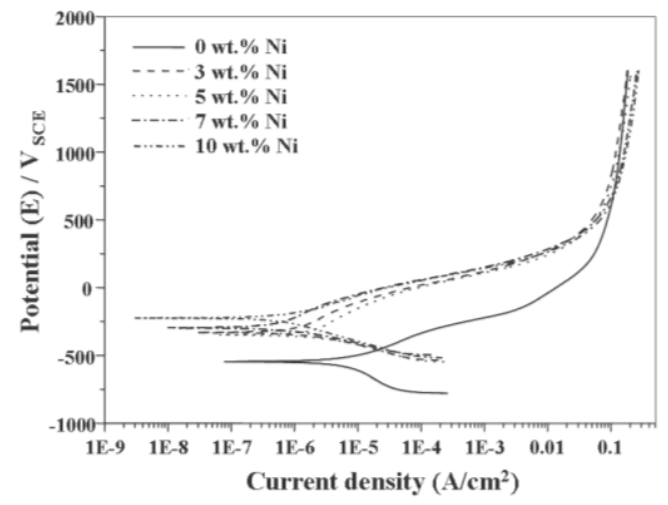

Fig. 4 Polarization curves of the alloys in the saline medium

\section{Conclusions}

This work set out to investigate the effect of Ni addition on the wear and corrosion resistance for Fe-20Cr-1.7C1Si hardfacing alloy. As expected, corrosion resistance of the alloy increased with increasing Ni concentration. In the meantime, wear resistance of the alloy did not decrease, even though the hardness decreased, with increasing $\mathrm{Ni}$ concentration up to $5 \mathrm{wt}$. \%. It was considered to be due to that the decrease of hardness was counterbalanced by work-hardening resulted from the strain-induced martensitic transformation. However, wear resistance of the alloy decreased abruptly with further increasing Ni concentration over $5 \mathrm{wt} . \%$.

\section{References}

[1] T. Prosser, "Riser system wear-An unrecognized drilling risk", Proc. of Drilling Technology-The next 100 years Conference, AADE 2001-01-NC-HO-06, Houston, Texas (2001)

[2] J. W. Yoo, S. H. Lee, C. S. Yoon and S. J. Kim, Journal of nuclear materials 352, 90 (2006)

[3] V. G. Novytskyy, Tribotest journal, 10, 265 (2004)

[4] T. Lesniewski, S. Krawiec, Wear, To be published (2007) 